\title{
Heart failure in sub-Saharan Africa: A clinical approach
}

\author{
S Kraus, ${ }^{1}$ FCP (SA); G Ogunbanjo, ${ }^{2}$ MFamMed, FCFP (SA); K Sliwa, ${ }^{1,3} \mathrm{MD}, \mathrm{PhD}$; N A B Ntusi, ${ }^{1}$ FCP (SA), DPhil \\ ${ }^{1}$ Division of Cardiology, Department of Medicine, Faculty of Health Sciences, University of Cape Town and Groote Schuur Hospital, Cape Town, \\ South Africa \\ ${ }^{2}$ Department of Family Medicine and Primary Health Care, Sefako Makgatho Health Sciences University, Pretoria, South Africa \\ ${ }^{3}$ Hatter Institute for Cardiovascular Research in Africa, Department of Medicine, Faculty of Health Sciences, Groote Schuur Hospital and \\ University of Cape Town, South Africa
}

Corresponding author: N A B Ntusi (ntobeko.ntusi@gmail.com)

\begin{abstract}
Despite medical advances, heart failure (HF) remains a global health problem and sub-Saharan Africa (SSA) is no exception, with decompensated HF being the most common primary diagnosis for patients admitted to hospital with heart disease. In SSA the in-hospital mortality rate of decompensated HF is up to $8.3 \%$. HF is a clinical syndrome that is caused by a diverse group of aetiologies, each requiring unique management strategies, highlighting the need for diagnostic certainty and a broad understanding of the complex pathophysiology of this condition. While there are a number of advanced medical, device and surgical interventions being tailored for HF internationally, the fundamental basic principles of HF management, such as patient education, effective management of congestion and initiation of diseasemodifying medical therapies, remain a challenge on our continent. This review addresses both the epidemiology of HF in SSA and principles of management that focus specifically on symptom relief, prevention of hospitalisation and improving survival in this population.

S Afr Med J 2016;106(1):23-31. DOI:10.7196/SAMJ.2016.v106i1.10325
\end{abstract}

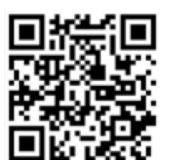

Heart failure (HF) is a major public health challenge, accounting for significant morbidity and premature mortality globally, including in sub-Saharan Africa (SSA). ${ }^{[1]}$ Owing to high prevalence and poor clinical outcomes, HF is associated with recurrent hospitalisation and substantial healthcare expenditure. ${ }^{[2]}$ In contrast to Western countries, where HF is considered a disease of older persons, in SSA it affects younger individuals. ${ }^{[1-3]}$ Acute decompensated HF is the most common primary diagnosis for patients admitted to hospital with heart disease in SSA, and it is encountered at all levels of care. ${ }^{[1,3,4]}$

The goals of the clinical approach to HF include: (i) correctly diagnosing the clinical syndrome of HF; (ii) identifying the underlying cause; and (iii) implementing an effective management strategy for symptom control, prolonging survival and reversing factors that predispose to precipitation of HF exacerbations.

\section{Definitions}

HF is a clinical syndrome of effort intolerance characterised by breathlessness and fatigue, due to structural and functional abnormalities of the myocardium, resulting in salt and water retention that is associated with neurohormonal adaptations, mainly in the reninangiotension-aldosterone system (RAAS).

Ejection fraction is the stroke volume (end-diastolic volume minus the end-systolic volume) divided by the end-diastolic volume. Systolic dysfunction is reduced contraction and emptying of the left ventricle, and diastolic dysfunction is impaired relaxation of the left ventricular myocardium resulting in impaired filling of the left ventricle.

\section{Epidemiology of HF in SSA}

Although there have been no population-based epidemiological studies of HF in Africa, there have been a number of hospital-based studies that give important insights into the incidence and prevalence of HF in SSA. In contrast to other parts of the world, non-ischaemic aetiologies are predominant, with hypertension, rheumatic heart disease (RHD) and cardiomyopathy accounting for two-thirds of cases of HF in hospitalised patients in the region..$^{[1,5]}$

\section{Classification of $\mathbb{H} \mathbb{H}$}

Patients with HF can be divided into two categories: HF with reduced ejection fraction (HF-REF), and HF with preserved ejection fraction (HF-PEF) (Fig. 1). Although there is poor correlation between symptom severity and left ventricular ejection fraction (LVEF), the LVEF carries independent prognostic significance and is considered abnormal when $<50 \%{ }^{[2]}$ The diagnosis of HF-PEF is more difficult, and although LVEF is normal or only mildly reduced in this condition, relevant structural heart disease and/or diastolic dysfunction should be present to make this diagnosis. Importantly, HF-PEF is a diagnosis of exclusion where other non-cardiac causes for patients' symptoms must be considered and discounted. ${ }^{[2]}$ Patients with HF-PEF are older, more often female and obese, and more likely to have hypertension and atrial fibrillation, compared to those with HF-REF, and their prognosis appears to be better overall. ${ }^{[6]}$

\section{Aetiology of HIF in SSA}

$\mathrm{HF}$ is a final common pathway for a number of conditions affecting the heart, and it is useful to classify the aetiology according to the following diseases: (i) hypertension; (ii) primary myocardial disease that includes cardiomyopathies and myocarditis; (iii) valvular heart disease; (iv) ischaemic heart disease; $(v)$ congenital heart disease; (vi) pericardial disease; and (vii) pulmonary hypertension ( $\mathrm{PH}$ ) (Table 1). It is important to consider alternative causes for fluid retention (e.g. renal or liver disease) and pulmonary oedema (e.g. neurogenic) in the context of a structurally normal heart.

\section{Pathophysiology}

Damage to cardiac myocytes and the extracellular matrix after myocardial injury results in pathological remodelling of the left ventricle with dilatation, impaired contractility, perfusion, fibrosis and electrical instability. If left untreated, these changes worsen over time, exacerbated by additional myocardial injury from neurohormonal imbalance resulting from activation of the RAAS and the sympathetic nervous system, increased cytokine expression, immune and inflammatory changes, altered fibrinolysis and oxidative stress. Reduced cardiac output results in arterial 


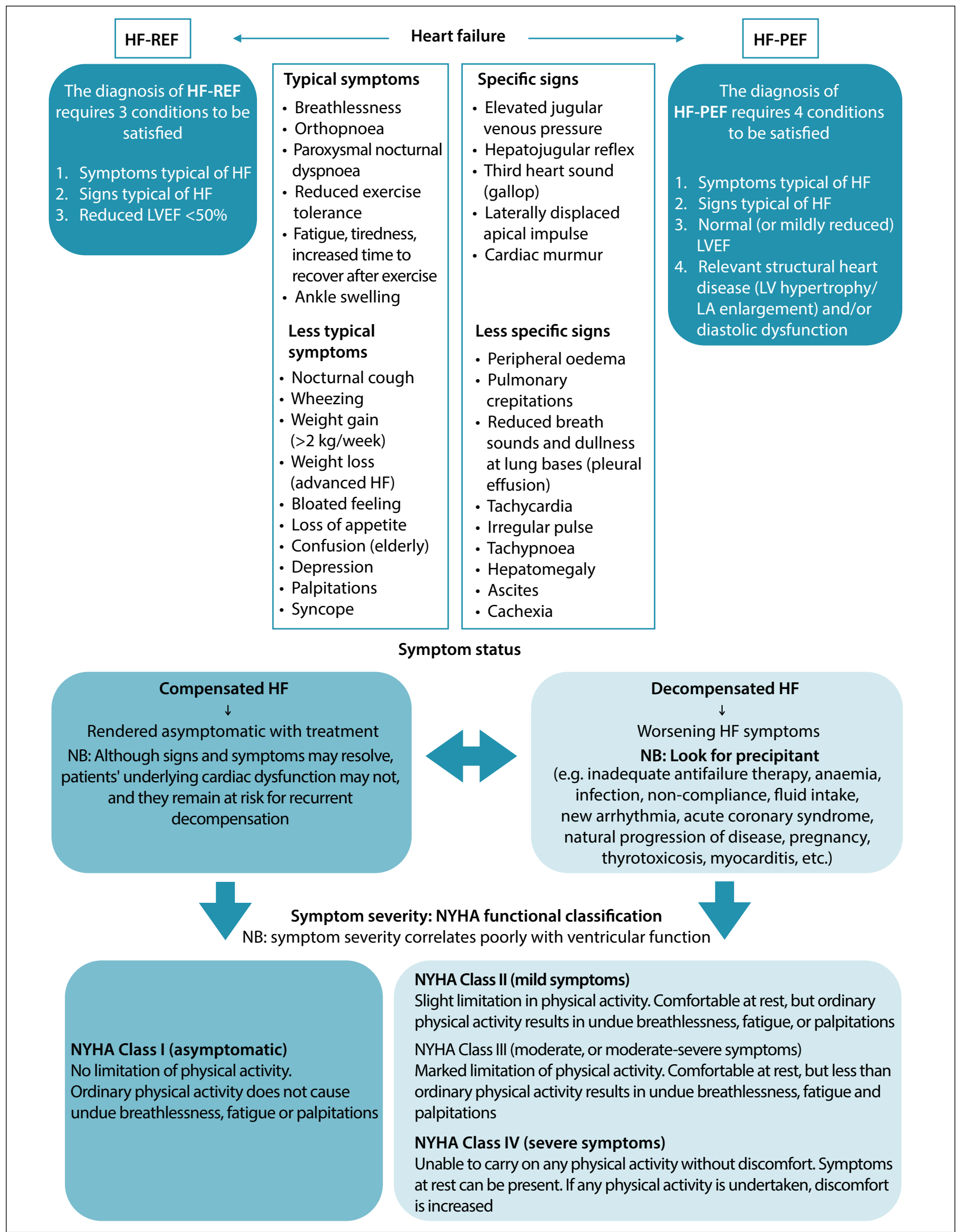

Fig. 1. Classification, clinical profile, grading of severity and natural history of heart failure (NYHA = New York Heart Association; LA = left atrial).

underfilling, leading to renal sodium and water retention via activation of the above-mentioned neuro-endocrine systems, in an attempt to restore arterial circulatory integrity (Fig. 2). ${ }^{[7]}$
Clinical presentation

The history is key in making the diagnosis of HF, grading symptom severity, and establishing not only the underlying cause but also identifying factors that may have precipitated decompensation (Table 2). The typical symptoms of HF are breathlessness, orthopnoea, paroxysmal 


\section{Table 1. Diseases causing heart failure}

\begin{tabular}{|c|c|}
\hline \multicolumn{2}{|l|}{ Hypertension } \\
\hline Essential hypertension & Unknown \\
\hline $\begin{array}{l}\text { Secondary } \\
\text { hypertension }\end{array}$ & $\begin{array}{l}\text { Primary aldosteronism (Conn syndrome), } \\
\text { Cushing syndrome, phaeochromocytoma, } \\
\text { chronic kidney disease, renal artery stenosis, } \\
\text { coarctation of the aorta, obstructive sleep apnoe }\end{array}$ \\
\hline \multicolumn{2}{|c|}{ Primary myocardial disease; cardiomyopathies and myocarditis } \\
\hline $\mathrm{HCM}$ & $\begin{array}{l}\text { Familial } \\
\text { Sporadic } \\
\text { Obesity, infants of diabetic mothers, amyloid } \\
\text { athletes }\end{array}$ \\
\hline $\mathrm{DCM}$ & $\begin{array}{l}\text { Familial } \\
\text { Non-familial } \\
\text { Alcohol, pregnancy, tachymyopathy, } \\
\text { thyrotoxicosis, myocarditis, nutritional } \\
\text { (e.g. thiamine, selenium), drugs (e.g. } \\
\text { anthracycline, cocaine), iron overload }\end{array}$ \\
\hline ARVC & $\begin{array}{l}\text { Familial } \\
\text { Non-familial }\end{array}$ \\
\hline RCM & $\begin{array}{l}\text { Familial } \\
\text { Non-familial } \\
\text { Endomyocardial fibrosis, radiation, amyloid, } \\
\text { carcinoid }\end{array}$ \\
\hline $\begin{array}{l}\text { Unspecified } \\
\text { cardiomyopathy }\end{array}$ & $\begin{array}{l}\text { Familial (left ventricular non-compaction) } \\
\text { Non-familial (Takotsubo cardiomyopathy) }\end{array}$ \\
\hline Myocarditis & $\begin{array}{l}\text { Infective } \\
\text { Viral, HIV, bacterial, fungal, helminths, } \\
\text { protozoa, rickettsia, spirochetes } \\
\text { Toxic/hypersensitivity } \\
\text { Anthracycline chemotherapy, alcohol, } \\
\text { methamphetamines, other drugs } \\
\text { Immune } \\
\text { Lupus, rheumatoid arthritis, sarcoidosis }\end{array}$ \\
\hline
\end{tabular}

Valvular heart disease

Rheumatic heart disease, endocarditis (infective and non-infective), degenerative, myxomatous, congenital

Ischaemic heart disease

Atherosclerosis
Spasm
Atherothrombosis
Coronary artery dissection

\section{Congenital heart disease}

Atrial septal defects, ventricular septal defects, transposition of the great vessels, tetralogy of Fallot, single ventricle, patent ductus arteriosis, etc.

Continued ...

nocturnal dyspnoea, reduced effort tolerance, fatigue, and ankle swelling. The New York Heart Association (NYHA) functional class allows a grading of symptom severity in a standardised manner (Fig. 1). ${ }^{[2]}$ Exploring past medical history, environmental exposures and family history may assist in deciphering a possible aetiology.

The physical examination findings may differ, depending on the underlying aetiology, but pedal oedema, raised jugular venous

\section{Table 1. (continued) Diseases causing heart failure}

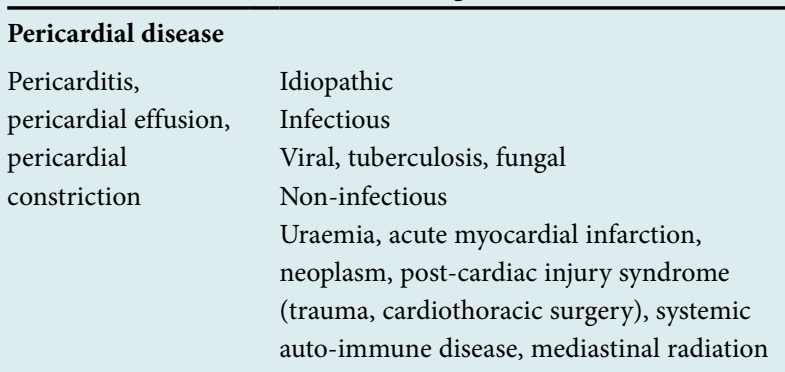

\section{Pulmonary hypertension}

Pulmonary arterial Idiopathic, heritable, drugs/toxins, associated hypertension

with connective tissue disease, HIV portal hypertension, CHD, schistosomiasis, chronic haemolytic anaemia, viral hepatitis

Pulmonary venoUnknown

occlusive disease

PH due to left heart Rheumatic heart disease disease

$\mathrm{PH}$ due to lung

disease and/or hypoxia

Chronic thromboembolic PH

PH with unclear and/ or multifactorial mechanism

HCM = hypertrophic cardiomyopathy; DCM = dilated cardiomyopathy; $\mathrm{ARVC}=$ arrhythmogenic right ventricular cardiomyopathy; $\mathrm{PH}=$ pulmonary hypertension; $\mathrm{CHD}=$ congenital heart disease; $\mathrm{RCM}=$ restrictive cardiomyopathy.

pressure, a tender hepatomegaly and basal crackles indicate congestive HF. Additional features that can be found on examination are listed in Table 3.

\section{Diagnostic tests in suspected. HI}

The baseline investigations recommended in clinical assessment of HF are outlined in Table 4. The electrocardiogram (ECG) and echocardiogram are the most useful investigations, as they confirm the presence of underlying structural heart disease. The likelihood of a normal ECG in a patient presenting with HF is low, making it an extremely helpful screening tool. ${ }^{[2]}$ It is recommended that all patients with a new diagnosis of HF undergo echocardiographic evaluation as it confirms the type of structural heart disease present and provides information on cardiac function. ${ }^{[2]}$

Understanding the aetiology of HF is vital when determining definitive management strategies and prognosis. The pursuit of a correctable cause and identification of reversible factors are central to improving outcomes in these patients. Patients with unexplained HF, particularly those who are not improving on standard therapy, should be referred for specialist review where advanced investigations can be done to establish a diagnosis (Table 4).

\section{Specific aetiologies of HIF}

\section{Hypertension}

Hypertension has been reported as the dominant cause of HF in Africa, responsible for up to $46 \%$ of cases of $\mathrm{HF}$ in hospitalised patients. ${ }^{[4,5,8]}$ Young hypertensive patients should be investigated for secondary causes of hypertension (Table 1). Standard anti-failure therapy and blood pressure control are the mainstays of therapy. 


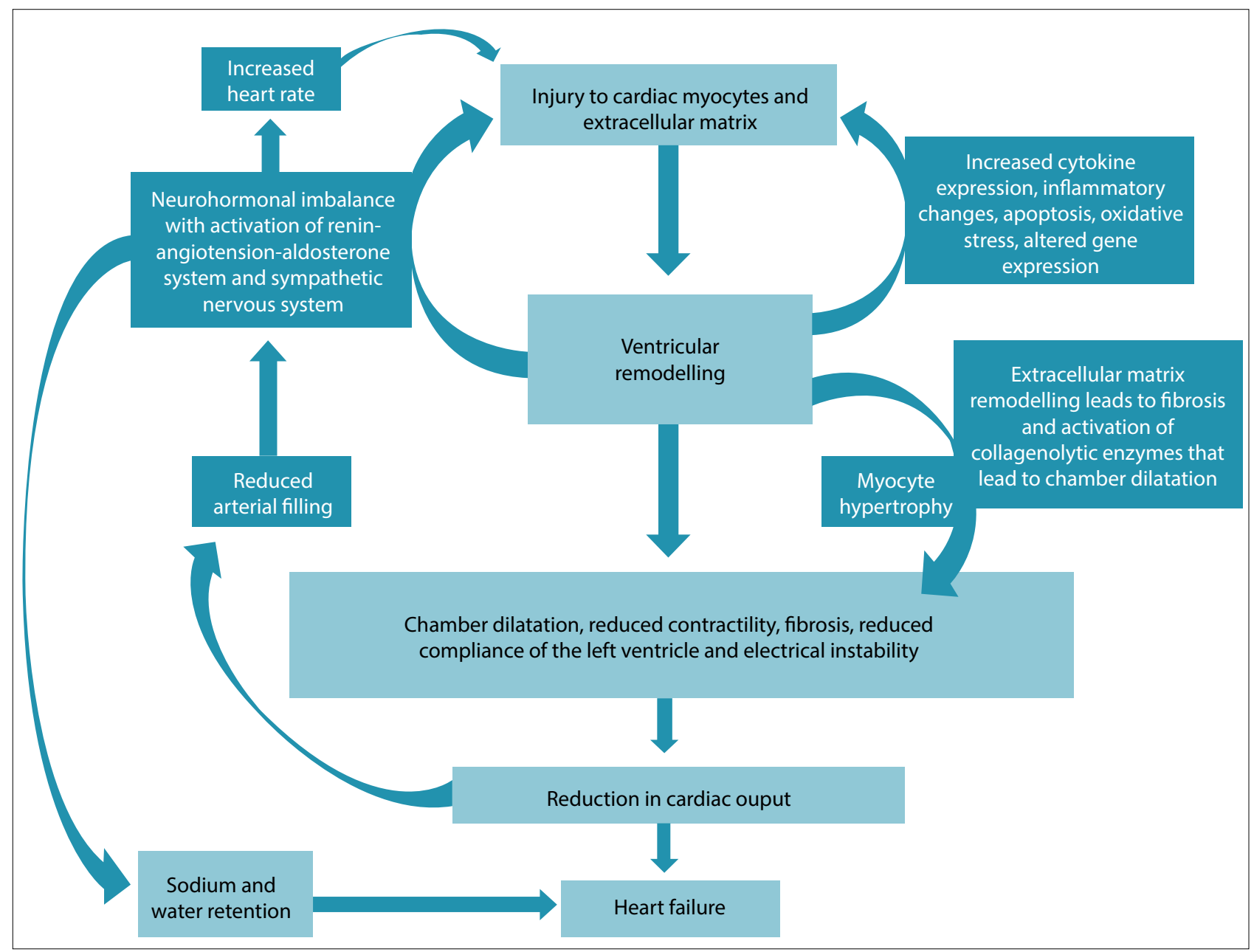

Fig. 2. Pathophysiology of heart failure.

\section{Cardiomyopathy}

Cardiomyopathy accounts for $20-30 \%$ of heart failure in Africans. ${ }^{[1]}$ Most commonly, patients who present with HF have a dilated phenotype, and potentially treatable causes for dilated cardiomyopathy should routinely be excluded (Table 1). Importantly, patients with other forms of cardiomyopathy (hypertrophic cardiomyopathy (HCM), arrhythmogenic right ventricular cardiomyopathy (ARVC), restrictive cardiomyopathy (RCM), and left ventricular non-compaction) presenting with HF should be referred for specialist review, as the management of these conditions is complex and multidisciplinary. ${ }^{[9]}$ Myocarditis should be considered in patients who present with cardiac symptoms and elevated cardiac biomarkers (troponin $\mathrm{T}$ or I), ECG abnormalities and/or evidence of functional impairment on echocardiogram, where acute coronary syndrome has been excluded. ${ }^{[10,11]}$ Forty-four percent of HIVassociated cardiomyopathy cases have evidence of myocarditis on endomyocardial biopsy, either as a result of HIV or secondary to opportunistic infections, ${ }^{[12]}$ justifying antiretroviral therapy in these patients.

\section{Valvular heart disease}

In contrast to Western populations, where valvular heart disease is mainly degenerative, in SSA valvular heart disease is predominantly caused by rheumatic fever and infective endocarditis. Despite a reduction in RHD as a cause of HF in SSA in recent years, it remains endemic on our continent. ${ }^{[13]}$ The mainstay of treatment for patients with symptomatic valvular heart disease is surgery, complemented by anti-failure therapy and secondary prevention of rheumatic fever with penicillin in RHD. All patients should be referred for evaluation for surgery.

\section{Ischaemic heart disease}

Ischaemic heart disease (IHD) is an uncommon cause of HF in SSA, accounting for only $7.7-9 \%$ of cases. ${ }^{[3,4,8]}$ Although IHD is considered uncommon among black Africans, there has been a notable rise in risk factors for atherosclerotic vascular disease in both urban and rural communities over the last few decades. ${ }^{[14]}$ Patients presenting with ischaemic left ventricular dysfunction require rigorous risk factor management in addition to conventional HF therapy. Patients

\begin{tabular}{l}
$\begin{array}{l}\text { Table 2. Precipitating factors to } \\
\text { consider in acute decompensated heart } \\
\text { failure }\end{array}$ \\
\hline Anaemia \\
Onset of a new arrhythmia (e.g. atrial \\
fibrillation/flutter, supraventricular \\
tachycardia, ventricular tachycardia) \\
Hyperthyroidism \\
Infection \\
Pregnancy \\
Infective endocarditis \\
Recurrence of rheumatic fever \\
Renal failure \\
Malignant hypertension \\
Myocardial infarction \\
Non-compliance on maintenance therapy
\end{tabular}

with suspected coronary artery disease with ongoing symptoms of angina should be referred to a cardiologist for consideration for revascularisation therapy. ${ }^{[2,15]}$

\section{Congenital heart disease}

Although the prevalence of congenital heart disease (CHD) in SSA is considered to be the lowest in the world, it is likely that this 
reflects the paucity of readily available estimates and that the true number of individuals affected with CHD is grossly underestimated. While CHD is an important cause of HF in children in SSA, it accounts for only a small percentage of cases of HF in adults. ${ }^{[16]} \mathrm{CHD}$ is riddled with complexity and requires management by experienced clinicians. ${ }^{[2]}$

\section{Pericardial disease}

Pericardial disease has a broad aetiology, but tuberculous pericarditis is the commonest cause of pericardial effusion, cardiac tamponade, and constrictive pericarditis in SSA, and carries a high mortality rate despite antituberculosis therapy, pericardiocentesis and pericardectomy. ${ }^{[17]}$

\section{Pulmonary hypertension}

$\mathrm{PH}$ is a debilitating progressive disease that leads to right HF, and although little is currently known about the epidemiology of $\mathrm{PH}$

\section{Table 3. Additional examination findings in heart failure}

\begin{tabular}{|c|c|}
\hline $\begin{array}{l}\text { Structural heart disease/ } \\
\text { aetiology }\end{array}$ & $\begin{array}{l}\text { Examination findings that could } \\
\text { be present }\end{array}$ \\
\hline $\begin{array}{l}\text { Conditions that result in left } \\
\text { ventricular dilatation and } \\
\text { systolic dysfunction }\end{array}$ & $\begin{array}{l}\text { Laterally displaced apex, a third } \\
\text { heart sound, cardiac murmur }\end{array}$ \\
\hline Pulmonary hypertension & $\begin{array}{l}\text { Palpable and/or loud pulmonary } \\
\text { component of the second } \\
\text { heart sound, parasternal heave, } \\
\text { pulmonary pathology, cyanosis, } \\
\text { clubbing }\end{array}$ \\
\hline Pericardial disease & $\begin{array}{l}\text { Elevated venous pressure, } \\
\text { pedal oedema and ascites, } \\
\text { unremarkable precordial } \\
\text { examination and clear lung fields } \\
\text { Pericardial rub may be present in } \\
\text { pericarditis } \\
\text { Hypotension, distended neck } \\
\text { veins, muffled heart sounds, and } \\
\text { pulsus paradoxus are suggestive } \\
\text { of pericardial effusion with } \\
\text { tamponade } \\
\text { Diastolic knock may be present in } \\
\text { constrictive pericarditis }\end{array}$ \\
\hline Congenital heart disease & $\begin{array}{l}\text { Depending on underlying cardiac } \\
\text { lesion; cardiac murmur, signs } \\
\text { of pulmonary hypertension, } \\
\text { parasternal heave (right ventri- } \\
\text { cular hypertrophy), fixed split of } \\
\text { the second heart sound (atrial } \\
\text { septal defect), cyanosis, clubbing, } \\
\text { surgical scars } \\
\text { Radial-radial delay, radial- } \\
\text { femoral delay may be present in } \\
\text { coarctation of the aorta }\end{array}$ \\
\hline Hypertensive heart disease & $\begin{array}{l}\text { Blood pressure may be elevated, } \\
\text { or normal in end-stage disease } \\
\text { Pressure-loaded apex beat, loud } \\
\text { aortic component of the second } \\
\text { heart sound, fourth heart sound } \\
\text { Evidence of target organ damage } \\
\text { (retinopathy, proteinuria) }\end{array}$ \\
\hline
\end{tabular}

in Africa, the reported incidence appears to be higher than in developed countries. The Pan African Pulmonary Hypertension Cohort study hopes to address the paucity of our knowledge. Importantly, many risk factors associated with $\mathrm{PH}$ are endemic in SSA (Table 1). ${ }^{[18]} \mathrm{PH}$ (not associated with left heart pathology) requires investigation in the absence of significant pulmonary disease.

\section{Management of HIF}

Although a significant portion of HF management falls within the realm of the general practitioner and general physician, it is important to be able to recognise which patients require specialist referral, particularly where there is diagnostic uncertainty and/or failure to improve, or deterioration, on anti-failure therapy.

The goals of treatment in patients with established HF are to: $(i)$ relieve symptoms with the aim to improve quality of life and functional capacity; (ii) prevent recurrent hospitalisations; and (iii) improve survival. In SSA these goals are achieved predominantly through patient education and medical therapy. Despite resource restraints, there is a role for advanced medical, device and surgical interventions, including orthotopic heart transplantation, for HF in SSA. It is important for

\section{Table 4. Investigations in heart failure}

\section{Baseline investigations}

Pro-BNP/BNP Elevated in heart failure

Not routinely required

Electrocardiogram Heart rate and rhythm disturbances

(atrial fibrillation/flutter)

Electrical conduction abnormalities

(left or right bundle branch block,

heart block)

Cardiac wall and/or chamber abnormalities

(ventricular hypertrophy, atrial enlargement, Q-waves)

Chest radiograph Cardiac size and shape (cardiomegaly)

Pulmonary congestion

Presence or absence of pulmonary pathology

Echocardiogram Chamber size

Systolic and diastolic function

Ventricular wall thickness

Valve morphology and function

\section{Advanced investigations}

Cardiovascular Cardiac structure, size and function

magnetic resonance Tissue characterisation

imaging

Perfusion imaging

Late gadolinium imaging (scar)

Velocity-encoded flow imaging

Defining anatomy in complex CHD

Cardiac computed Coronary artery angiography

tomography

Nuclear medicine Cardiac function (right and left ventricular imaging

ejection fraction)

Myocardial perfusion studies

Angiography Haemodynamic assessment

Coronary artery angiography

Endomyocardial Histological diagnosis

biopsy

$\mathrm{BNP}=$ brain natriuretic peptide; $\mathrm{CHD}=$ congenital heart disease 
Table 5. Patient education

Patients should be well informed about:

What heart failure is and why symptoms occur

The underlying cause of their heart failure

Prognosis

The treatment options available to them

Patients must be educated about:

Medications, specifically the role of each drug used to treat heart failure

Fluid retention and how to manage it (i.e. how to restrict fluids, monitor weight and

adjust diuretic therapy accordingly)

Remembering the names, doses and frequency of medication they are on or bringing the drugs to hospital with them

Patients should be encouraged to make realistic decisions regarding:

Their ability to work. Temporary or permanent disability grant applications should be made if anticipated time away from work is $\geq 6$ months

Financial implications related to loss of employment or added healthcare costs

Legal issues in the event of their death

Obtaining medical aid, where possible

Patients are at increased risk of depression and may require referral for counselling or antidepressant drug therapy

Exercise

An active lifestyle should be encouraged

Heart rate monitoring can be helpful in guiding patients with regard to safe levels of exercise Aiming for a maximum heart rate of $(180$ - age - 20) beats/minute during exercise is recommended

Excessive alcohol consumption should be discouraged and excessive use of caffeine/stimulants avoided

The dangers of illicit drug use should be addressed

In women, pregnancy and contraception should be discussed:

Contraception is recommended in all patients with cardiac disease

Women need to be well informed of the dangers of pregnancy, particularly in the setting of

LVEF $<45 \%$, pulmonary hypertension or mitral stenosis

Patients should be informed that medication used to treat heart failure, such as ACE

inhibitors, are teratogenic

Patients who strongly desire a pregnancy, or who have fallen pregnant inadvertently, should

be referred to a specialist centre for assessment

Pregnant patients with underlying cardiac disease are at extremely high risk and require a

multidisciplinary team (cardiologist, obstetrician, anaesthetist) to manage them throughout their pregnancy, during delivery and post partum

clinicians to familiarise themselves with the indications and the availability of services. ${ }^{[2]}$

\section{Patient education}

It is the attending clinicians' responsibility to inform patients about their condition. Important aspects to consider are listed in Table 5.

\section{Optimising medical therapy}

Medical therapy consists of two components: (i) disease-modifying drugs consisting of three neurohormonal antagonists (angiotensinconverting enzyme (ACE) inhibitors (or angiotensin receptor blockers), beta-blockers, and mineralocorticoid receptor antagonists) that are fundamental in modifying the course of disease and improving survival; and (ii) symptomatic therapies, such as diuretics and digoxin, that relieve congestion, reduce hospitalisation and improve quality of life.

Fig. 3 illustrates an approach for the medical management of HF. The first step is to manage and alleviate congestion. Diseasemodifying drugs should be introduced at recommended starting doses and titrated up to maximum tolerated doses over a number of weeks (Table 6). ${ }^{[2]}$ Digoxin has been shown to relieve symptoms and reduce hospitalisations, ${ }^{[19]}$ but is associated with an increase in mortality in HF patients. ${ }^{[20]}$ Current guidelines recommend low-dose digoxin in selected patients who remain symptomatic despite optimal ACE inhibitor and betablocker therapy. Hypokalaemia and renal failure predispose patients to digoxin toxicity, and its use is contraindicated in these circumstances. ${ }^{[21]}$

The prognosis of acute decompensated HF remains poor, with greater severity of congestion being associated with worse outcomes. Acute decompensated HF is associated with an in-hospital mortality rate of up to $8.3 \%$ in Africa. ${ }^{\left[{ }^{[}\right]}$Fluid retention and congestion are responsible for $90 \%$ of $\mathrm{HF}$ hospital admissions, and even with diuretic therapy approximately $40 \%$ of patients are discharged with unresolved congestion. ${ }^{[22]}$

The mainstay therapy for the treatment of congestion is loop diuretics. Diuretic resistance is the failure to adequately control salt and water retention despite appropriate dose escalation of loop diuretics. The doseresponse curve for loop diuretics shifts in HF, resulting in the need for increased doses of the drug to achieve a therapeutic effect; thus inadequate dosing must be differentiated from diuretic resistance. Infrequent dosing can result in rebound salt and water retention, which can be addressed by increasing the frequency of dosing or changing to a continuous intravenous infusion.

Strategies for overcoming diuretic resistance include the addition of thiazide diuretics and/or spironolactone. Importantly, diuretic combinations can result in severe volume depletion and electrolyte disturbances, and should only be used in circumstances where volume status and electrolytes can be monitored. RAAS activation plays an important role in sodium and water retention by increasing distal sodium reabsorption in the kidney. Introducing ACE inhibitors is crucial in managing congestion. The challenge is maintaining adequate arterial blood pressure, as low blood pressure drives plasma renin activity and further activation of RAAS (Fig. 4). ${ }^{[22]}$

\section{Advanced medical, device and surgicall interventions}

Heart rate reduction improves clinical outcomes in HF. Beta-blocker dosage should be titrated to maintain a resting heart rate $<75$ beats/minute. In instances where patients are unable to tolerate increased doses of beta-blockers, ivabradine can be considered. Ivabradine inhibits the $\mathrm{I}_{\mathrm{f}}$ channel in the sinus node and can be used to slow the heart rate in patients in sinus rhythm. ${ }^{[2]}$

Indications for device and surgical interventions are listed in Table $7 .^{[2,23]}$

\section{Conclusion}

$\mathrm{HF}$ is a common condition that is caused by a diverse group of aetiologies, representing unique disease entities that require different management strategies. It is for this reason 


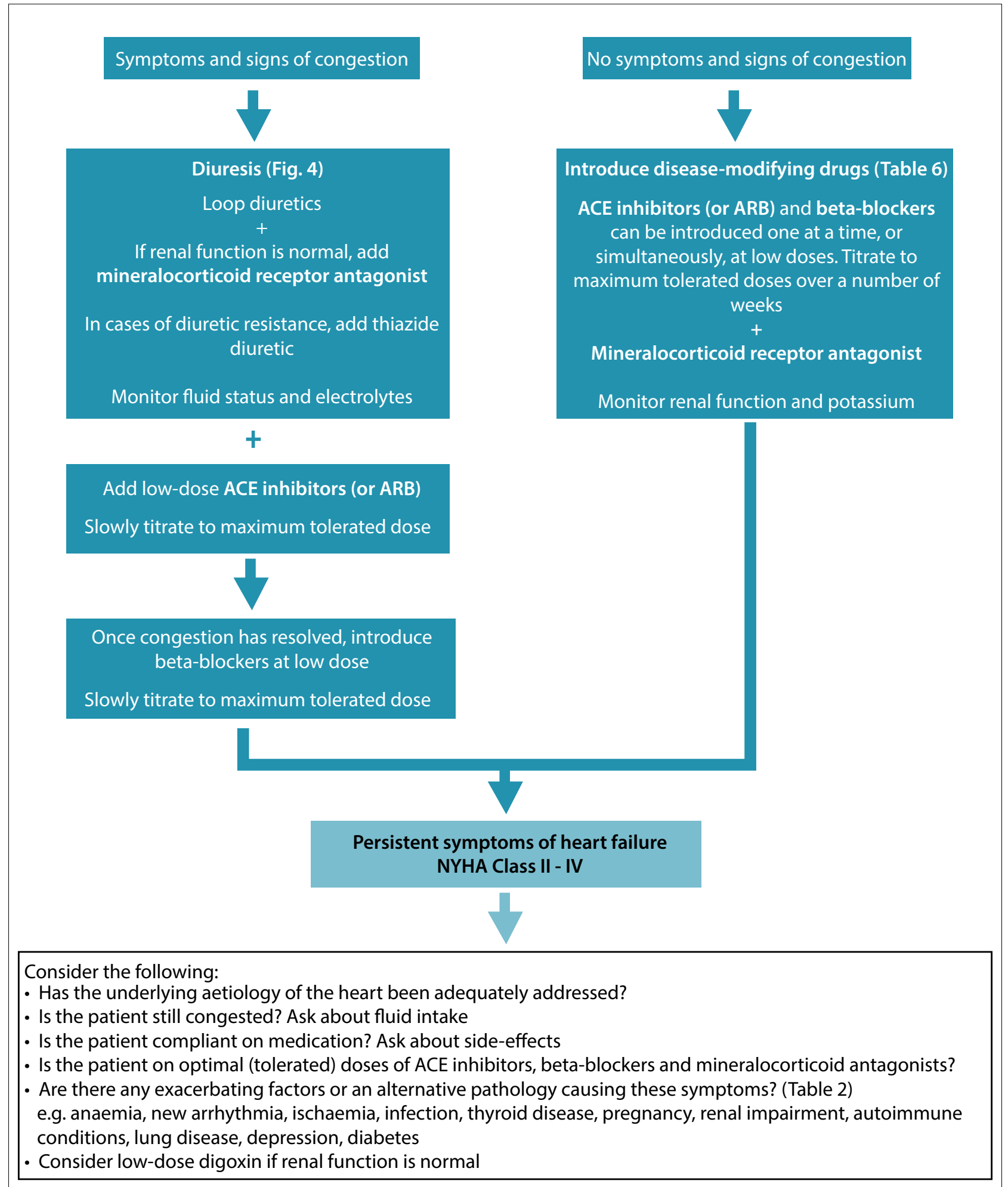

Consider the following:

- Has the underlying aetiology of the heart been adequately addressed?

- Is the patient still congested? Ask about fluid intake

- Is the patient compliant on medication? Ask about side-effects

- Is the patient on optimal (tolerated) doses of ACE inhibitors, beta-blockers and mineralocorticoid antagonists?

Are there any exacerbating factors or an alternative pathology causing these symptoms? (Table 2)

e.g. anaemia, new arrhythmia, ischaemia, infection, thyroid disease, pregnancy, renal impairment, autoimmune conditions, lung disease, depression, diabetes

low-dose digoxin if renal function is norma

\section{ASSESSMENT BY CARDIOLOGIST \\ CONSIDERATION FOR DEVICE AND/OR SURGICAL INTERVENTION, INCLUDING TRANSPLANTATION (Table 7) Sinus rhythm and heart rate $\geq 75$ beats/minute $\rightarrow$ consider ivabradine \\ Refractory heart failure, QRS duration $>120 \mathrm{~ms}$ and LVEF $\leq 35 \% \rightarrow$ consider cardiac resynchronisation therapy}




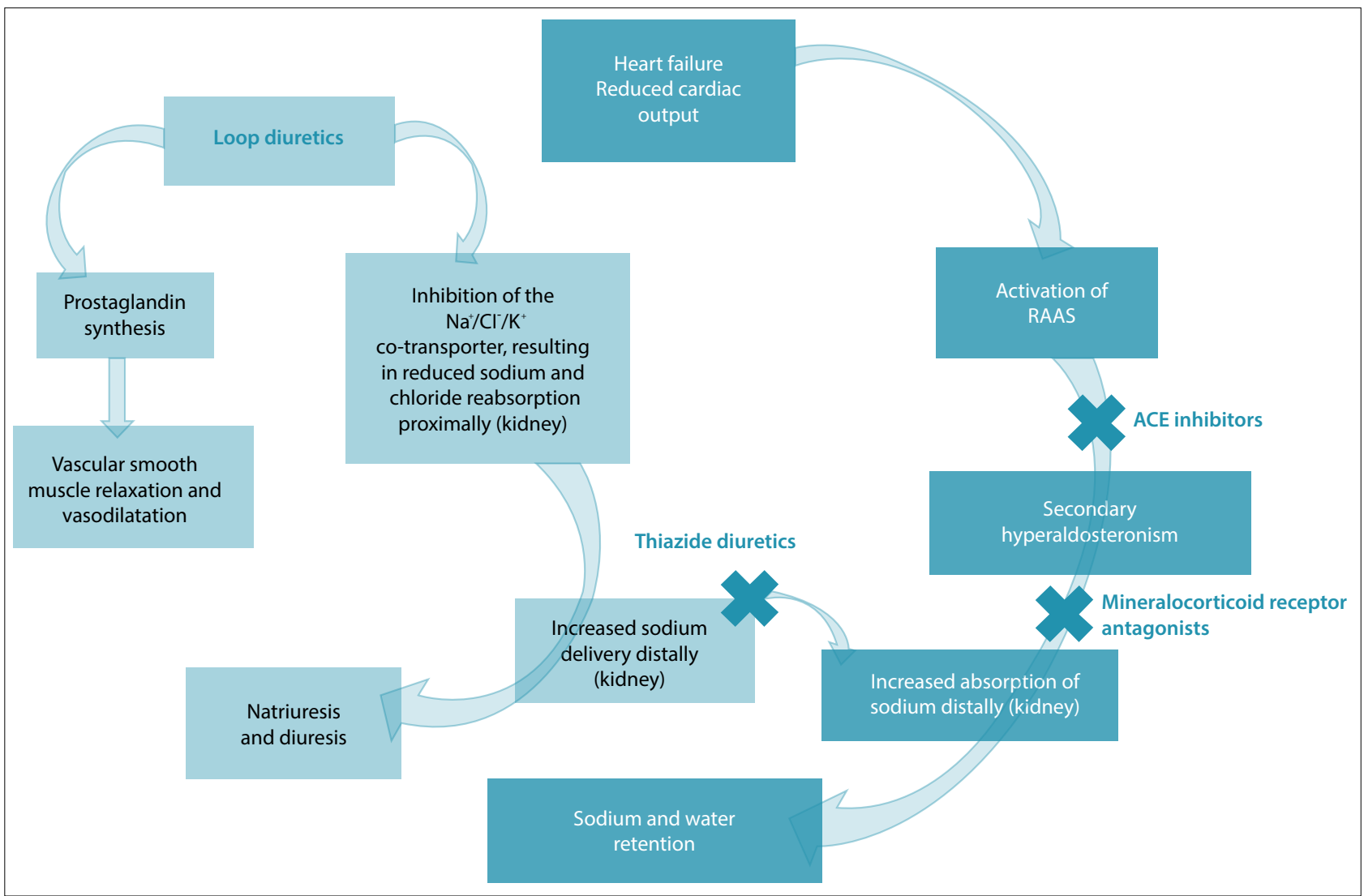

Fig. 4. Mechanisms of action of pharmacotherapy used in heart failure management.

\section{Table 6. Disease-modifying drugs used in heart failure ${ }^{[2]}$}

\begin{tabular}{|c|c|c|c|c|}
\hline Drugs & Starting dose & Target dose & Recommendation & $\begin{array}{l}\text { Level of } \\
\text { evidence }\end{array}$ \\
\hline \multicolumn{5}{|l|}{ ACE inhibitors } \\
\hline Captopril & $6.25 \mathrm{mg} 3 \times /$ day & $50 \mathrm{mg} 3 \times /$ day & Recommended, in addition to beta-blockers, for all patients with & IA \\
\hline Enalapril & $2.5 \mathrm{mg} 2 \times /$ day & $10-20 \mathrm{mg} 2 \times /$ day & LVEF $\leq 40 \%$ to reduce risk of HF hospitalisation and premature death & \\
\hline Lisinopril & $2.5-5.0 \mathrm{mg}$ daily & 20 - 35 mg daily & & \\
\hline Perindopril & $2.0 \mathrm{mg}$ daily & $4.0 \mathrm{mg}$ daily & & \\
\hline Ramipril & $2.5 \mathrm{mg}$ daily & $5.0 \mathrm{mg} 2 \times /$ day & & \\
\hline Trandolapril & $0.5 \mathrm{mg}$ daily & $4.0 \mathrm{mg}$ daily & & \\
\hline \multicolumn{5}{|l|}{ Beta-blockers } \\
\hline Bisoprolol & $1.25 \mathrm{mg}$ daily & 10 mg daily & Recommended, in addition to ACE inhibitors, for all patients with & IA \\
\hline Carvedilol & $3.125 \mathrm{mg} 2 \times /$ day & $25-50 \mathrm{mg} 2 \times /$ day & LVEF $\leq 40 \%$ to reduce risk of HF hospitalisation and premature death & \\
\hline $\begin{array}{l}\text { Metoprolol } \\
\text { succinate }\end{array}$ & 12.5 - $25 \mathrm{mg}$ daily & $200 \mathrm{mg}$ daily & & \\
\hline \multicolumn{5}{|c|}{ Angiotensin II receptor blockers } \\
\hline Candesartan & $4 \mathrm{mg}$ or $8 \mathrm{mg}$ daily & $32 \mathrm{mg}$ daily & Recommended as an alternative to ACE inhibitors, in patients with & IA \\
\hline Valsartan & $40 \mathrm{mg} 2 \times /$ day & $160 \mathrm{mg} 2 \times /$ day & LVEF $\leq 40 \%$ to reduce risk of HF, hospitalisation and premature death & \\
\hline Losartan & 50 mg daily & $150 \mathrm{mg}$ daily & & \\
\hline Telmisartan & 20 mg daily & $80 \mathrm{mg}$ daily & & \\
\hline \multicolumn{5}{|c|}{ Mineralocorticoid receptor antagonists } \\
\hline $\begin{array}{l}\text { Spirono- } \\
\text { lactone }\end{array}$ & 25 mg daily & 25 - $50 \mathrm{mg}$ daily & $\begin{array}{l}\text { Recommended for all patients with persisting symptoms and an } \\
\text { LVEF } \leq 35 \% \text { despite treatment with an ACE inhibitor and a beta- }\end{array}$ & IA \\
\hline Eplerenone & 25 mg daily & 50 mg daily & blocker to reduce risk of HF hospitalisation and premature death & \\
\hline
\end{tabular}

that diagnostic certainty is as important as treating the clinical syndrome of HF. Effective diuresis and complete resolution of congestion is key in improving symptoms and functional capacity, reducing the need for recurrent hospitalisation, increasing the probability of establishing patients on good doses of disease-modifying drugs, and ultimately improving outcomes. 
Table 7. Device and surgical interventions in heart failure ${ }^{[2,23]}$

\begin{tabular}{|c|c|}
\hline Intervention & Indication \\
\hline ICD & $\begin{array}{l}\text { Secondary prevention } \\
\text { Survivors of cardiac arrest or patients with sustained symptomatic ventricular tachycardia, irrespective of LVEF } \\
\text { Good functional status } \\
\text { Expected survival }>1 \text { year } \\
\text { Primary prevention (limited availability in SSA) } \\
\text { LVEF } \leq 35 \% \\
\text { Symptomatic (NYHA Class II - III) despite } \geq 3 \text { months on optimal medical therapy } \\
\text { Increased risk of SCD in conditions such as ARVC and HCM }\end{array}$ \\
\hline CRT & $\begin{array}{l}\text { Cardiac resynchronisation therapy should be considered in patients who fulfil the following criteria } \\
\text { Typical LBBB (QRS } \geq 120 \mathrm{~ms} \text { ) } \\
\text { Persistent symptoms despite } \geq 3 \text { months of optimal medical therapy } \\
\text { NYHA Class III/IV (ambulatory) } \\
\text { LVEF } \leq 35 \% \text { and an expected survival }>1 \text { year } \\
\text { Right bundle branch block and prolonged PR interval are predictors of non-favourable outcomes }\end{array}$ \\
\hline Mechanical circulatory support & $\begin{array}{l}\text { Limited availability in SSA } \\
\text { Drug-refractory acute circulatory collapse and at immediate risk of death } \\
\text { To sustain life, as a bridge to decision/candidacy for transplantation or as a bridge to transplantation, recovery or } \\
\text { destination therapy }\end{array}$ \\
\hline Heart transplantation & $\begin{array}{l}\text { End-stage heart failure with severe symptoms, a poor prognosis, and no remaining alternative treatment option } \\
\text { Motivated, well-informed, and emotionally stable } \\
\text { Capable of complying with the intense treatment required postoperatively } \\
\text { Contraindications to transplantation } \\
\text { Active infection, significant comorbidities (e.g. severe peripheral vascular disease, cerebrovascular disease, } \\
\text { renal failure, liver disease, systemic multiorgan disease), recurrent thromboembolism, unhealed peptic ulcer, } \\
\text { current alcohol or drug abuse, emotional/psychiatric instability, cancer within the previous } 5 \text { years } \\
\text { High, fixed pulmonary vascular resistance ( }>4-5 \text { Wood units and mean transpulmonary gradient }>5 \mathrm{mmHg} \text { ) }\end{array}$ \\
\hline
\end{tabular}

Funding. This manuscript is not funded. Dr N A B Ntusi acknowledges support from the National Research Foundation and Medical Research Council of South Africa.

\section{References}

1. Ntusi NB, Mayosi BM. Epidemiology of heart failure in sub-Saharan Africa. Expert Rev Cardiovasc Ther 2009;7(2):169-180. [http://dx.doi.org/10.1586/14779072.7.2.169]

2. McMurray IJ, Adamopoulos S, Anker SD, et al. ESC guidelines for the diagnosis and treatment of acute and chronic heart failure 2012. The Task Force for the Diagnosis and Treatment of Acute and Chronic Heart Failure 2012 of the European Society of Cardiology. Developed in colltabortion with

3. Sliwa $\mathrm{K}$, Wilkinson D, Hansen C, et al. Spectrum of heart disease and risk factors in a black urban population in South Africa (the Heart of Soweto Study): A cohort study. Lancet 2008;371(9616):915922. [http://dx.doi.org/10.16/S0140-6736(08)60417-1]

4. Damasceno A, Mayosi BM, Sani M, et al. The causes, treatment, and outcome of acute heart failure in 1006 Africans from 9 countries. Arch Intern Med 2012;72(18):1386-1394. [http://dx.doi.org/10.1001/ archinternmed.2012.3310

5. Sliwa K, Mayosi BM. Recent advances in the epidemiology, pathogenesis and prognosis of acute heart failure and cardiomyopathy in Africa. Heart 2013;99(18):1317-1322. [http://dx.doi.org/10.1136/ heartjnl-2013-303592]

6. Meta-analysis Global Group in Chronic Heart Failure. The survival of patients with heart failure with preserved or reduced left ventricular ejection fraction: An individual patient data meta-analysis. Eur Heart J 2012;33(14):1750-1757. [http://dx.doi.org/10.1093/eurhearti/ehr254]

7. McMurray JJ. Clinical practice. Systolic heart failure. N Engl J Med 2010;362(3):228-238. [http:// dx.doi.org/10.1056/NEJMcp0909392]

8. Callender T, Woodward M, Roth G, et al. Heart failure care in low- and middle-income countries: A systematic review and meta-analysis. PLoS Med 2014;11(8):1001699. [http://dx.doi.org/10.10.1371/ journal.pmed.1001699]

9. Kraus S, Ntusi NA. Specialist multidisciplinary hypertrophic cardiomyopathy clinics: Should they be the standard of care? Intern Med J 2015;45(3):237-238. [http://dx.doi.org/10.10.1111/imj.12686]

10. Cooper LT Jr, Keren A, Sliwa K, Matsumori A, Mensah GA. The global burden of myocarditis. Part 1 A systematic literature review for the Global Burden of Diseases, Injuries, and Risk Factors 2010 study. Global Heart 2014;9(1):121-129. [http://dx.doi.org/10.1016/j.gheart.2014.01.007]
11. Kindermann I, Barth C, Mahfoud F, et al. Update on myocarditis. I Am Coll Cardiol 2012;59(9):779792. [http://dx.doi.org/10.1016/j.jacc.2011.09.074]

12. Shaboodien G, Maske $\mathrm{C}$, Wainwright $\mathrm{H}$, et al. Prevalence of myocarditis and cardiotropic virus infection in Africans with HIV-associated cardiomyopathy, idiopathic dilated cardiomyopathy and heart transplant recipients: A pilot study: Cardiovascular topic. Cardiovasc J Afr 2013;24(6):218-223. [http://dx.doi.org/10.5830/cvja-2013-039]

13. Sliwa K, Carrington M, Mayosi BM, Zigiriadis E, Mvungi R, Stewart S. Incidence and characteristics of newly diagnosed rheumatic heart disease in urban African adults: Insights from the Heart of Soweto study. Eur Heart J 2010;31(6):719-727. [http://dx.doi.org/10.1093/eurheartj/ehp530]

14. Mayosi BM, Flisher AJ, Lalloo UG, Sitas F, Tollman SM, Bradshaw D. The burden of noncommunicable diseases in South Africa. Lancet 2009;374(9693):934-947. [http://dx.doi.org/10.1016/ S0140-6736(09)61087-4]

15. Task Force on Myocardial Revascularization of the European Society of, Cardiology, et al. Guidelines on myocardial revascularization. Eur J Cardiothorac Surg 2010;38(Suppl):S1-S52. [http://dx.doi. org/10.1016/i.ejcts.2010.08.019]

16. Zuhlke L, Mirabel M, Marijon E. Congenital heart disease and rheumatic heart disease in Africa: Recent advances and current priorities. Heart 2013;99(21):1554-1561. [http://dx.doi.org/10.1136/ heartjnl-2013-303896]

17. Mayosi BM, Ntsekhe M, Bosch J, et al. Prednisolone and Mycobacterium indicus pranii in tuberculous pericarditis. N Engl J Med 2014;371(12):1121-1130. [http://dx.doi.org/10.1056/NEJMoa1407380]

18. Thienemann F, Dzudie A, Mocumbi AO, et al. Rationale and design of the Pan African Pulmonary hypertension Cohort (PAPUCO) study: Implementing a contemporary registry on pulmonary hypertension in Africa. BMJ Open 2014;4(10):e005950. [http://dx.doi.org/10.1136/bmjopen-2014-005950] 19. Digitalis Investigation. The effect of digoxin on mortality and morbidity in patients with heart failure. N Engl J Med 1997;36(8):525-533. [http://dx.doi.org/10.1056/NEJM199702203360801]

20. Vamos M, Erath JW, Hohnloser SH. Digoxin-associated mortality: A systematic review and meta-analysis of the literature. Eur Heart J 2015;36(28):1831-1838. [http://dx.doi.org/10.1093/eurhearti/ehv143]

21. Mkoko P, Mokhele N, Ntsekhe M, Ntusi NA, Digoxin therapy in the modern management of cardiovascular disease: An unusual but serious complication. S Afr Med J 2015;105(2):154. [http:// dx.doi.org/10.7196/samj.8638]

22. Felker GM, Mentz RJ. Diuretics and ultrafiltration in acute decompensated heart failure. J Am Coll Cardiol 2012;59(24):2145-2153. [http://dx.doi.org/10.1016/j.jacc.2011.10.910]

23. Dickstein K, Vardas PE, Auricchio A, et al. 2010 focused update of ESC Guidelines on device therapy in heart failure: An update of the 2008 ESC Guidelines for the diagnosis and treatment of acute and chronic heart failure and the 2007 ESC Guidelines for cardiac and resynchronization therapy. Developed with the special contribution of the Heart Failure Association and the European Heart Rhythm Association. Eur J Heart Fail 2010;12(11):1143-1153. [http://dx.doi.org/10.1093/eurjhf/hfq192] 